Jean-Louis Comolli 
Publicado en la revista Images documentaires, № 23, 1995.

\section{¿Mi enemigo preferido?}

\section{CERO}

¿Filmar al enemigo? ¿Para qué, si no es para combatirlo mejor? ¿Mediante otras armas, y no las del cine? Siendo como es un agente de conocimiento y de descubrimiento, ¿el cine no puede atravesar las defensas del enemigo, exponer sus fortalezas y sus debilidades, desmontar sus resortes, hacer aparecer sus contradicciones, desenmascarar sus ardides y sus amenazas? ¿Conocerlo para combatirlo mejor, filmarlo para conocerlo mejor? Es casi todo lo que el cine, me parece, puede y sabe hacer en el terreno de las luchas sociales o políticas. Lo demás: conciencia, acción, movilización, pertenece, más allá del espectador, al sujeto y al ciudadano. ¿Cómo filmar entonces a "su" enemigo? La pregunta del "cómo", es una verdadera pregunta de cineasta.

\section{UNO}

A veces sucede (felizmente), que el enemigo que elige el cineasta (que elige para filmar), no sea el suyo solamente, y sea el enemigo de muchos más: Hitler en Man Hunt, de Fritz Lang, o El gran Dictador, de Chaplin. Más recientemente, un nazi, o los nazis en Wundkanal de Thomas Harlan o Notre nazi, de Robert Kramer ${ }^{(1)}$, Pinochet y sus fascistas en Chili impressions, de José María Berzosa; Bruno Megret y el Front National en La campagne de Provence ${ }^{(2)}$...

Los filmes citados en primer lugar son películas de ficción. No es casualidad: el enemigo es más fácil de abordar -o encarar- en una ficción que en un documental. Por otra parte tal es la predilección del cine de ficción por los "enemigos" que uno de los asuntos mayores -míticos- puede ser formulado como "los enemigos el uno contra el otro".(3) Dos razones a la vez explican esta atracción mutua, y marcan el abismo que separa aún hoy en día al documental de la ficción. La primera razón es que el enemigo filmado en el documental no está interpretado por actores, está ahí "de verdad", "en carne y hueso", presencia real frente a la cámara, amenaza o engaño o seducción, pero también un pedazo de humanidad, quizá odiosa u odiable, pero humanamente viviente. Mediante los gestos, los enganches y las duraciones, un filme opera una especie de disección. Detallado por la puesta en escena, anatomizado por el montaje, el malo aparece por lo que es, un sujeto incómodo, un bloque de individuo desmenuzado, personaje despedazado por los demonios que lo poseen... Arte humanista (es un pleonasmo), el cine reconoce lo humano en el hombre, aún en el peor enemigo, quizá simplemente porque frente a la máquina el hombre, aún el peor, no puede ser sino humano.

La segunda razón es que filmar a este enemigo real supone que esté más o menos de acuerdo (a veces sucede que los partidos políticos piden que se los filme, durante las campañas electorales). Preparándose para filmar, y antes de filmar a "su enemigo", el documentalista está obligado a establecer una relación con él, exactamente igual que si se tratara de un amigo o una persona neutra, a quienes se propone filmarla.

Qué tipo de relación, y cómo conducirla, compromete la responsabilidad del cineasta, y ayuda a construir el filme. "Filmar al enemigo" en un documental presenta una serie de riesgos reales -hostilidad o, al contrario, lo que es más grave, connivencia, complacencia-. Riesgos que no son los mismos que en la ficción, porque el contrato que se celebra con el actor para hacer de un cierto personaje, y recibir un salario, libera al cineasta de la tentación o del deseo de iden- 
tificarse/oponerse al cuerpo real de un hombre real (el actor), pudiendo así interesarse solo en el cuerpo real de un hombre virtual (el personaje encarnado por el actor). No es del mismo orden la negociación que se realiza con el enemigo que se encarna a sí mismo, que con el actor que encarna al enemigo. Es más simple y menos peligrosa en este segundo caso. El actor representa al personaje en la escena del filme. Es su metáfora viviente. Un cuerpo por otro cuerpo. El documental debe, por el contrario, consumar un sacrificio no metafórico. Las cosas están ahí y solo valen por ellas mismas; terriblemente presentes, los cuerpos no se dejan dirigir fácilmente.

Filmar, para el cine documental, es entonces filmar una relación que se establece entre una máquina y dos sujetos - dos cuerpos (por lo menos)-, el que filma y el que es filmado. ¿Qué quiere decir, en el caso de dos enemigos, establecer esta relación y filmarla? Quiere decir que no es solamente previa al rodaje, como fundadora de su misma posibilidad, sino que ella misma es lo que se filma, testimonia de ella misma, de esa relación. Si mi enemigo y yo "somos dos", ese "dos" filmado tiene una especie de suplemento que es la propia relación entre "uno" y "el otro".

\section{DOS}

El otro, mi otro, quizá bueno, o malo, o un poco de cada uno, o mucho de los dos. Puedo, en efecto, establecer o no una relación con él. Puedo quererlo o detestarlo, adoptarlo o combatirlo, desearlo o ignorarlo, reformarlo o condenarlo. ¿Y el otro, que es filmado? En el cine no estamos frente a frente, el otro y yo. Estamos lado a lado, de un lado y otro del mismo filme. Un filme nos une. Espectador, hago que el filme actúe. Y el otro actúa dentro de ese filme. Una puesta en escena aparece como el tercero, en nuestro dúo. La pantalla es un espejo, nos separa menos que lo que nos reúne. Representación = lo que está entre el uno y el otro, lo que fabrica tanto de uno como del otro, en un juego de sube y baja entre dos deseos, dos necesidades, dos movimientos - moción de identidad/moción de alteridad. ${ }^{(4)}$ El otro se convierte en mi deseo del otro, el otro en mi deseo. Para decirlo rápidamente: en el cine, el reverso es siempre cómplice. El filme, cinta de Moebius concretada, nos hace deslizar en el mundo perturbador de lo reversible. Los órdenes, las jerarquías, las certezas, los sentimientos, los valores, pueden convertirse en lo contrario durante una proyección, y esto no se hace sin nosotros. En el transcurso del filme, puede suceder que el espectador se encuentre confrontado con el principio de vacilación, que caracteriza sus propias oscilaciones, sus dudas, todo lo que no está resuelto, que hace y deshace cada sujeto comprometido en una continua iniciación. Es evidente toda la importancia de la dimensión subjetiva puesta en juego en la experiencia cinematográfica. El cine confronta con el enemigo filmado, algo que pertenece a la intimidad del espectador. Si existe la violencia de la representación, está ahí, en lo que implica de "nosotros" en "el otro".

\section{TRES}

Tratándose de amigos y enemigos, de buenos y malos, la fórmula de la reversibilidad cinematográfica es conocida: "el que pierde, gana". El motivo mítico de la transformación de la fortaleza en debilidad, y de la debilidad en fortaleza, pasó del teatro (Shakespeare, 
Beaumarchais, Musset...) al cine (Lang, Renoir, Rohmer...), como un juego cruel y como una técnica de conocimiento. Instalados en la escena, moldeados por la representación, los monstruos y los enemigos son, si no más amables o soportables, por lo menos un poco mejor conocidos o reconocidos: aquí y aho$\mathrm{ra}$, en esta pantalla que no es solamente la del fantasma, ¿no se trata de descubrir algo lo que nos separa y también, quizá, de lo que nos une?

Hay un ejemplo famoso: "el innoble Batala" de Le crime de Monsieur Lange, filme que es de Renoir no por casualidad, ese cineasta-desequilibrista de Une partie de campagne, La carrosse d'or $O$ Le testament du Docteur Cordelier. Tal como está encarnado por el actor Jules Berry, Batala es evidentemente más seductor y mejor personaje que el pobre señor Lange, héroe tristemente positivo. Batala aparece mentiroso, estafador, cínico y vil, pero eso no importa, es el ganador. Es el falo. Sostiene el filme él solo. Cuántas más cosas hace, me intereso cada vez más en sus bajezas. ¿Por qué? Antes que nada, porque él realiza esas bajezas, en un filme. Iba a escribir: para un filme. Porque las canalladas de Batala me llegan, filmadas, en una luz que quizá hace brillar un poco demasiado sus ojos; porque se encarnan en las poses ventajosas de un cuerpo que lleva quizá demasiado ostensiblemente su poder de seducción; porque, resumiendo, los gestos, las palabras, las mímicas de ese canalla explícito que es Batala, se dirigen hacia mí como nimbados por un aura de paradójica fragilidad que es la propia marca del juego -y que me hace sentir, cómica y desesperada, toda humana, "demasiado humana”, dimensión-. ¿Cómo? Todo el juego de Jules Berry (genial) no es para ser Batala, o para hacerme creer que lo es, sino, más brechtiano que esas simples apariencias, para decirme: he aquí lo que es Batala, cómo es, hasta qué punto es innoble. "He aquí Batala" me señala un ser de puesta(s) en escena. Las que vienen de él: engaños, maniobras, trampas; y la que, realizada por Renoir, me relaciona, como espectador, con ese personaje, y así deseo que fracasen sus trampas, pero gozo con sus éxitos.

\section{CUATRO}

La expresión "he aquí" marca una irremediable diferencia entre la cosa y su representación. Señala claramente el índex del cine que señala al mundo ${ }^{(5)}$. El rayo de luz que traza formas en una pantalla nos muestra que nos muestra. Es el índice de una representación y de la amenaza que la mina. Actúa como el marco alrededor de la imagen, el círculo de luz mágica alrededor de la escena, la flecha que denuncia el defecto de la coraza. Lo que se llama "performance", aún brillante y sólida, solo nos es dada escoltada, y como duplicada por el sentimiento de su fragilidad, de su precariedad; puede romperse en cualquier momento, puede pararse, va a terminar alguna vez, en la catarsis o en la decepción... Representados, el poder y la fortaleza lo son, pero con la amenaza que planea sobre ellos en lo que está fuera de la escena, la amenaza de su límite o de su decrepitud. El subrayado de lo que está en la escena, señala también sus límites. Designada y ofrecida al gozo del espectador, la escena aparece confortada, protegida, asegurada; sin embargo, en el mismo gesto, se señala la inminencia, apenas diferida, de su ruina. 


\section{CINCO}

Amigos o enemigos, los personajes de un filme comparten este ambiguo destino escénico (lo mejor y lo peor de la escena, el pleno y el vacío de la representación, comienzo y fin, presencia y ausencia). No solamente pertenecen al mismo filme, sino a menudo al mismo cuadro (los combates, los duelos). Nace entre ellos una especie de comunidad cinematográfica ${ }^{(6)} Y$ aunque reducida al único beneficio de la representación, esta comunidad los acerca. Más allá de todos los enfrentamientos. Más que todas las reconciliaciones. Desde el momento en que son filmados juntos, la distancia que separa al amigo del enemigo es más imaginaria que real. $Y$ esta distancia se reduce aún más cuando, espectador, yo los veo en el filme, porque ellos se aproximan de mi mirada. La ambigüedad es indispensable en el cine, es constitutiva de su mecanismo, y es gracias a ella que la división del sujeto-espectador puede conducir a la emoción de descubrirse otro uno mismo, y que el propio otro es diferente del que uno imaginaba...

\section{SEIS}

Con el descentramiento del cine, desheredado por los medios y menos poderoso desde el momento en que las televisiones lo han aliviado del fardo de las representaciones de masa, llega el momento de una reversibilidad que ya no tiene más necesidad de nuestra ambigüedad -la nuestra- y que substituye a nuestras dudas, una duda objetiva y generalizada, un equívoco establecido. Ya no es más (tiempo del cine), el eco de la representación que duplica la cosa representada para afectarla de una perturbación y de una amenaza (ver más adelante). Igual que ayer, hoy la representación no es lo real (Barthes), pero no se contenta con alejarse de lo real, o alejarse para ocupar su lugar, como en la época del filme-mundo: en el circuito sin fin de la información-mercancía, toda cosa representada tiende a cambiar de signo. Verdadero o falso, real o virtual, presente o posible, los cambios de signo se generalizan. ${ }^{(7)}$

Cambio tras cambio $=$ modo cada vez más errático de la circulación y de la producción de sentido. Un ejemplo: la denuncia de las ignominias y crímenes ordinarios del partido fascista francés, se encuentra transformada en un argumento de seducción suplementario. Denuncia y denegación forman parte de una pareja cómplice (y perversa): la denuncia que lo señala, permite sin embargo al acusado negar sus actos (denegación), beneficiándose con lo que anuncia, e incluso un doble beneficio, porque ha habido un doble anuncio: el que hizo la acusación duplicado por la protesta por su inocencia. Todo acto efectuado y denegado, juega así dos veces y en dos sentidos: positiva y negativamente. Hay un pasaje al acto (los adeptos del movimiento no se equivocan), y hay al mismo tiempo la denegación empecinada del acto (y los mismos adeptos tampoco se equivocan). Resultado: la denegación retoma la confesión y la da vuelta, convirtiéndola en contra-propaganda (es lo que pasó después del asesinato de Ibrahim Ali( ${ }^{(8)}$, en Marsella en febrero de este año. [1995].

\section{SIETE}

Este tintineo de los signos en las representaciones mediáticas, rechaza al cine como heredero de la escena real de la antigua representación, la que fabrica un tercero entre el otro y yo, y uno puede preguntar- 
se si es posible, hoy en día, filmar al enemigo del presente. Esa relación de la que hablaba ¿no está ahora pervertida de antemano?

Frente a estas dudas, lo único que puedo oponer, aun cuando parezca débil, es un acto de fe en la fuerza del cine, capaz, me parece, de volver a fabricar escena ahí, donde estaba destruida. Por más hábil que sea para deslizarse en lo virtual, el enemigo tiene siempre un cuerpo, y está siempre obligado (es un rasgo arcaico del juego político) a exponer ese cuerpo como presencia real frente a una cámara. Está obligado a producir sus propias puestas en escena, porque siempre hay escena en la relación política. El cine sigue sabiendo tomar, describir, analizar estas puestas en escena, para hacerlas legibles.

Pienso en el bello filme de Berzosa, Les pompiers de Santiago ${ }^{(9)}$, que deja siempre el beneficio de la puesta en escena al adversario: Pinochet, el secretario del Cuerpo de Bomberos, un terrateniente, etc. Estos personajes están filmados en su decorado, su luz, según su propio dispositivo, con los trajes que han elegido, su tono, su ritmo y a veces su música, sosteniendo un punto de vista con sus propias palabras, y enunciado su profesión de fe con la mayor buena conciencia. Lo que dicen no es refutado por las preguntas del cineasta, que se limita solamente a precisar esos dichos. Estos dignos representantes de una elite fascista representados con todo su poderío y en su propia puesta en escena, están en el poder, tienen el poder, y lo exhiben, con todo lo que supone de gusto por el decorado, por la jerarquía, con cinismo, con egoísmo. Como en un cuerpo a cuerpo reglado por una secreta estética zen, el trabajo del cineasta se despliega en esa especie de retirada, que obliga al adversario a avanzar, y a desenmascararse un poco más.
A partir del momento en que se encarna y se representa, un poder se convierte en su propia caricatura. No hay necesidad de exagerar el trazo, que ya es exagerado. En Marseille en mars ${ }^{(10)}$ diversas secuencias de la campaña electoral puntúan, como leitmotiv, las deambulaciones de los personajes. Una de las escenas, filmada por un equipo del Canal 2 francés, muestra a Le Pen recorriendo un mercado, sonriente, amable con sus admiradores. Cerca de él, un guardaespaldas, para protegerlo, lo roza. Le Pen se sobresalta, y un rictus violento aparece en su rostro: "iTe dije que no me tocaras!iNo me gusta que me toquen!" El gesto y la palabra fóbicos, filmados, descubren de repente otra escena, algo que amenaza, detrás de las sonrisas y la bonhomía. Aquí se muestra la relación de la idea política con el cuerpo político, relación que solo el cine puede establecer y desplegar. Los argumentos, los análisis, los temas ideológicos, los actos incluso, se encuentran hoy, ya lo dije, tomados por lecturas siempre revisables. Entramos en efecto en una era de revisionismo generalizado (tal como lo describe Baudrillard). Contra esta virtualización de los referentes, las débiles fuerzas del cine no pueden hacer nada, salvo, designando la vanidad, manifestar la ruina y la pérdida de esa vanidad (Primer plano de Abbas Kiarostami).

En un mundo en que toda prueba puede ser desmentida por una prueba contraria, una contra-prueba, "la prueba por la imagen", no es más que un engaño. Como toda imagen oscila hasta el infinito (verdadero/falso, etc.), la escena cinematográfica gira en la espiral sin fin de la ambigüedad. Por una parte el cine retira las realidades referenciales y las vuelve más ambiguas; por otra parte, relanza esta ambigüedad como fortaleza de la representación. Sucede que, obligado por el 
juego de las identificaciones, el enemigo, en su poderío, tiene todavía necesidad de constituir las escenas de su representación. En ese lugar el cine lo espera, y se mide con él. Vertov y Eisenstein contra Stalin.

\section{ОСНO}

Una vez filmado ¿el enemigo es menos enemigo? ¿Inclinación fatal del cine, que no puede filmar juntos al uno y al otro (obsesión baziniana ${ }^{(11)}$ ), salvo que los acerque y que me los acerque? Hay una repetida obstinación humanista del cine, que lo opone a los medios de comunicación masivos, incluyendo la televisión. Las diferentes encarnaciones actuales del diablo (el terrorista, el extremista, el fanático, el criminal, el drogadicto, el extranjero, etc.) son mostrados con el dedo insistentemente, y eso es quizá por una especie de oscuro objeto de un deseo social, que los convierte en enemigos indispensables, que se trata de cazar y que, sin embargo, son necesarios, y se los condena con un enérgico vade retro, pero para hacerlos volver, y poder así diferenciarnos de ellos.

En el cine sucede lo contrario: el enemigo es domesticado, y no conjurado. Si la censura funciona bien, en nuestras sociedades autopolicíacas ${ }^{(12)}$, como una confesión, si levantar el secreto de sumario es la exageración que condimenta la confesión (Deadline, de Richard Brooks, 1952) la condena, a la inversa ino toma el sentido paradójico de una especie de llamado de auxilio? ¿Y la (bien llamada) "diabolización" del enemigo, no se vuelve su publicidad, y lo refuerza? Retomo la cuestión de La Campagne de Provence. Se trataba de filmar -en entrevistas, y en situaciones de la campaña electoral- a diversos representantes del Front National, que trataban de ganar la región.
El principio establecido al comienzo, para todos los partidos políticos por igual era: filmar con un objetivo normal, situaciones públicas, con entrevistas que se desarrollaran en público, como las situaciones teatrales que suceden al costado de la situación principal. Siempre presente la cuestión de la relación: se trataba de no tener ninguna relación de complicidad o de intimidad con ninguno de aquellos a quien filmábamos: a palabra pública (la política), cinematografía pública. Igual distancia para todos. Tratamiento único. Tantas buenas intenciones terminaron por pesarnos. A medida que las semanas pasaban, que el plan de batalla del Front National aparecía más claramente, sentíamos que debíamos enfrentar cinematográficamente esta ofensiva en regla. Las performances de Mégret, por ejemplo, desbordaban nuestro dispositivo de distancia igualitaria. Y estuvimos tentados no de abandonar ese dispositivo, sino de modificarlo un poco. Aunque más no fuera para no aparecer ante nuestros propios ojos, como cómplices de lo que filmábamos. Las reuniones públicas en las que se proferían monstruosidades, por ejemplo. Entonces nos parecía que cierta violencia de los encuadres podían dar cuenta de la violencia de las palabras. $O$ que cierta iluminación extraña acentuaba ciertos delirios. Era sin duda mostrarnos ingenuos y militantes. Hoy, tres años después y con una mayor adhesión popular al Front National, esta especie de manierismo que quería subrayar la distancia que habíamos establecido con aquellos que filmábamos, me parece un esfuerzo vano. ¿Demasiado lejos/demasiado cerca: vieja cuestión de la puesta en escena, sube y baja, el que pierde gana? La cuestión de la guerra es otra. El cine no puede responder a la guerra por otro medio que no sea la crítica de la guerra. Al enemigo no se le puede dar rostro humano. 


\section{Notas}

(1) El filme de Thomas Harlan me produce un gran malestar: un verdadero nazi acepta actuar su propio rol -le pagan como a un actor- en un filme que no solamente lo denuncia, sino que busca "hacerle pisar el palito", es decir hacerle confesar -y confesar que se arrepiente- que es culpable de la muerte de miles de personas. Una especie de "proceso privado", como cuando se dice una "proyección privada". Toda la maquinaria se pone en marcha: interrogatorios, voz en off insistente, luces enceguecedoras, etc., estamos en una cámara de tortura... Sometido a esta tortura, el nazi, que es el verdadero malo, no deja de ser una víctima; víctima, en todo caso, de este filme. Y aún más, porque la tortura sensorial y psicológica del "personaje", lo es, también para el espectador del filme, obligado a sufrir y expiar, a su manera, también él. Como el cine (eso lo veremos después) no puede dejar de sentir compasión, finalmente siento piedad por aquel que debería horrorizarme. Malestar. El filme de Robert Kramer Notre nazi se instala en ese dispositivo torcido. Despliega ese malestar hasta la náusea: reacciones confusas o piadosas del equipo de filmación de Harlan, ambigüedades, conflictos sin resolver (¿hay que comer con el nazi, darle la mano, hablarle?). Diría que el enemigo, privado de su fuerza, vaciado de su sustancia, se convierte en alguien como uno, el malestar de un sujeto perturbado. Y esta verdad muy banal pero perturbadora impide al filme de Kramer que salga del ida y vuelta entre la fascinación y la repulsión, para poder superar así el psicodrama.

(2) Documental sobre las elecciones regionales francesas de 1992, y la ofensiva del Front National. Escrito, actuado, filmado y montado en nueve meses, de junio de 1991 a marzo de 1992, junto con Anne Baudry y Michel Samson, y exhibido una semana después de la segunda vuelta, por el Canal 3 de televisión.

(3) La lista de estos filmes, si se la estableciera, sería más larga que la de los documentales que "filman al enemigo". Por ejemplo: algunas de las ficciones contemporáneas más conocidas del nazismo: Capa y espada y Los verdugos también mueren, de Fritz Lang, Ser o no ser de Ernst Lubitsch, Honeymoon de Leo McCarey, Kühle Vampe de Dudlow y Brecht, La vie est à nous de Renoir, Saboteador y Tuyo es mi corazón (Notorius) de Hitchcock. Pantallazo rápido, seguramente olvido algunos, la lista es bastante larga.

(4) Pierre Legendre (1995) Dieu au miroir. Étude sur l'institution des images, Paris, Fayard.

(5) Serge Daney (1983) La rampe, Cahiers du Cinéma, Gallimard.

(6) Ver "L'écran du fantasme", Serge Daney, (1983) La rampe, Cahiers du Cinéma, Gallimard.

(7) Sobre estas cuestiones, remito a los últimos textos de Jean Baudrillard y de Paul Virilio.

(8) Joven oriundo de las Islas Comores, asesinado por militantes del Front National. Crimen y negación.

(9) En la serie Chili impressions.

(10) Documental sobre las elecciones legislativas de 1993 en Marsella. Escrito y realizado con Anne Baudriy y Michel Samson. Exhibido en el Canal 3 de Marsella.

(11) Ver sobre esta cuestión "Sur Salador", de Serge Daney, en La Rampe, Cahiers du Cinéma/Gallimard, 1983.

(12) Michel Foucault: Surveiller et punir y La volonté de savoir. 